\title{
A COMPARATIVE STUDY ON THE PHYSICAL AND MECHANICAL PROPERTIES OF DAHURIAN LARCH AND JAPANESE LARCH GROWN IN KOREA
}

\author{
Seong Hyun Kim, Do Hoon Kim, Jae Ik Jo, Jong Ho Kim, Seung Hwan Lee \\ Jung Kee Choi, Nam Hun Kim \\ Kangwon National University \\ Republic Of Korea \\ (Received July 2020)
}

\begin{abstract}
To compare the wood quality of Dahurian larch and Japanese larch growing in Korea, the physical and mechanical properties were examined using the Korean standards. The proportion of heartwood was $82 \%$ and $72 \%$ in Dahurian and Japanese larch, respectively. The percentage of latewood was $42 \%$ in Dahurian larch and 35\% in Japanese larch. The growth ring width of Dahurian larch was narrower than that of Japanese larch. Dahurian larch showed about $20 \%$ higher green moisture content compare to Japanese larch wood. Density and shrinkage of Dahurian larch were higher than Japanese larch. Axial compression strength, young`s modulus in compression, and shearing strength in heartwood of Dahurian larch were $11 \mathrm{MPa}$, $686 \mathrm{MPa}$, and $2.3 \mathrm{MPa}$, respectively, showing higher value than Japanese larch. The hardness was in the range of 13.8-38.7 MPa in Dahurian larch and 17.7-48.4 MPa in Japanese larch. The compression strength parallel to the grain and shearing strength in both species were significantly correlated with oven-dried density. Besides, the hardness in Dahurian larch was significantly correlated with latewood percentage and oven-dried density. In conclusion, the differences in the properties of both species were revealed and the results can be used for quality indices of both wood species.
\end{abstract}

KEYWORDS: Dahurian larch, Japanese larch, physical and mechanical properties, quality indices, wood quality. 


\section{INTRODUCTION}

The Larix species is a deciduous tree belonging to the Pinaceae family and is distributed worldwide with about 10 species in the Northern Hemisphere's major regions, such as Alaska, Russia, Mongolia, China, Japan, and Korea (LePage and Basinger 1995). In Korea, there are two species: Dahurian larch (Larix gmelinii), which is native to the Korean Peninsula, and Japanese larch (Larix kaempferi), introduced from Japan. The wood of Larix species has high value as a wood resource because of its excellent quality and straight stem forms. It is used for various purposes, such as post and timber of buildings, flooring, furniture, deck, laminated veneer lumber (LVL), medium density fiberboard (MDF), oriented strand board (OSB), and railroad ties (Chauret et al. 2002, Hwang et al. 2008). The Dahurian larch is sparsely distributed in the mountainous areas of North Korea and in a limited area of South Korea (Hwang and Park 2007). A few studies have been undertaken on the properties of Dahurian larch wood as building material (Hwang and Park 2007, Hwang et al. 2008), its wood characteristics (Chauret et al. 2002) and its physical and mechanical properties of lumber (Zhou et al. 2015, Ishiguri et al. 2019, Han et al. 2019) for its effective utilization. Japanese larch, first introduced in Korea in 1904, is one of the major afforestation species and the most valuable domestic wood material in Korea. It is commonly known as an allied species to the Dahurian larch (Shin and Kim 2003, Jung and Park 2008). Japanese larch is usually used as an alternative to the Dahurian larch as building members, structural materials, and wood pellets, among other uses. There are many studies on the properties of Japanese larch wood for its value-added utilization, such as wood quality (Kwon et al. 2004, Ishikura et al. 2012), enhancing properties for wood-based materials (Wang et al. 2017, Song and Hong 2018), fuel characteristics for wood pellets (Kim et al. 2015) and characteristics of preservation (Choi et al. 2011).

To date, however, there have been few comparative studies on the wood quality of Dahurian larch and Japanese larch growing in Korea (Han et al. 2017). Therefore, in this study, the physical and mechanical properties of these two species were investigated and compared to provide basic data that can be used as wood quality indices for their efficient utilization.

\section{MATERIAL AND METHODS}

\section{Material}

Design principle

Three trees for each species of both Dahurian larch and Japanese larch were harvested from the research forest of Kangwon National University, Chuncheon, Korea (N 37 $77^{\circ}$, E 127 $\left.81^{\circ}\right)$. Discs of about 7 to $9 \mathrm{~cm}$ thickness were collected from breast height. The characteristics of the wood samples are shown in Tab. 1 .

Tab. 1: Basic information of the sampled trees.

\begin{tabular}{|l|c|c|c|c|}
\hline \multicolumn{1}{|c|}{ Common name } & Botanical name & Age (years) & Height (m) & D.B.H. (cm) \\
\hline Dahurian larch & Larix gmelinii (Rupr.) Kuzen. & 72 & $20-22$ & $32-33$ \\
\hline Japanese larch & Larix kaempferi (Lamb.) Carriere & 38 & $20-22$ & $34-36$ \\
\hline
\end{tabular}

Note: D.B.H. - Diameter at breast height. 


\section{Methods}

Measurement of physical properties

The heartwood proportion was obtained using the following Eq. 1:

$$
\mathrm{HP}=\frac{W t-W h}{W t} \times 100 \quad(\%)
$$

where: $\mathrm{w}_{\mathrm{t}}$ - weight of the original discs $(\mathrm{g}), \mathrm{w}_{\mathrm{h}}$ - weight of heartwood proportion $(\mathrm{g})$.

Growth ring width and latewood percentage in four directions on the discs were measured by KS F 2202 (2016). Moisture content (KS F 2199, 2016), density and specific gravity (KS F 2198, 2016), and shrinkage of woods (KS F 2203, 2004) were measured in sapwood and heartwood. In each test of physical properties, defect-free wood specimens of 38 pieces in Dahurian larch and 40 pieces in Japanese larch were used.

\section{Measurement of mechanical properties}

According to the axial compressive properties (KS F 2206, 2004) and shearing strength (KS F 2209, 2004), test specimens were manufactured in the size of $20(T) \times 20(\mathrm{R}) \times 30(\mathrm{~L}) \mathrm{mm}$ in sapwood and heartwood of both species. The specimens for hardness were manufactured in the size of $30(\mathrm{~T}) \times 30(\mathrm{R}) \times 15(\mathrm{~L}) \mathrm{mm}$ in sapwood and heartwood of both species (KS F 2212, 2004). The specimens were stored in a constant temperature and humidity chamber $\left(20 \pm 2^{\circ} \mathrm{C}\right.$, $65 \pm 3 \%$ ) for 5 weeks. Compressive properties and shearing strength were measured using an Instron U.T.M. (Model No. 4482) under a load speed of $1.5 \mathrm{~mm} \cdot \mathrm{min}^{-1}$. In the shear test, the shear fracture was a tangential section. The number of specimens used in the compression and shear tests were 40 and 44 pieces in Dahurian larch and 48 and 40 pieces in Japanese larch, respectively. Hardness was measured by the Brinell method at 6 points per section using an Instron U.T.M. (Model No. 4482) under a load speed of $0.5 \mathrm{~mm} \cdot \mathrm{min}^{-1}$. The number of specimens used in the hardness test were 72 in Dahurian larch and 66 in Japanese larch.

\section{Statistical analysis}

One-way ANOVA and Duncan's multiple tests were undertaken using the IBM SPSS Statistics 24.0, 2016 software to check the significance of the test results of the physical and mechanical properties between the two species. In the correlation analysis, a p-value less than or equal to 0.05 indicated significance.

\section{RESULTS AND DISCUSSION}

\section{Physical properties}

Heartwood proportion, growth ring width, and latewood percentage

The heartwood proportion, growth ring width, and latewood percentage of Dahurian larch and Japanese larch wood are shown in Tab. 2. The heartwood proportions were $82 \%$ and $72 \%$ in Dahurian and Japanese larch wood, respectively. The growth ring widths were $2.5 \mathrm{~mm}$ and $4.3 \mathrm{~mm}$ for Dahurian larch and Japanese larch wood, while the latewood percentages were $42 \%$ and $35 \%$, respectively. Dahurian larch wood showed higher heartwood proportion and latewood percentage, and narrower growth ring width than Japanese larch wood. Pazdrowski et al. (2007) described the heartwood proportion of European larch (Larix decidua) wood as 57-70\% which was a little smaller than this study. Hwang et al. (2008) and Hwang and Park (2007) reported the growth ring width of Dahurian larch wood as 0.6-1.5 mm. Han et al. (2017) also reported the growth ring width and latewood percentage of Dahurian larch wood as $1.02 \mathrm{~mm}$ and $40.3 \%$, 
and those of Japanese larch wood as $2.09 \mathrm{~mm}$ and $31.9 \%$, respectively. In addition, Kwon et al. (2004) explained the growth ring width of Japanese larch wood as $2.83 \mathrm{~mm}$ which was like the results of this study.

Tab. 2: Macroscopic characteristics of the sample wood species.

\begin{tabular}{|l|c|c|c|}
\hline \multicolumn{1}{|c|}{ Species } & Heartwood proportion (\%) & Growth ring width (mm) & Latewood percentage (\%) \\
\hline Dahurian larch & $82 \pm 2$ & $2.5 \pm 1.7$ & $42 \pm 9$ \\
\hline Japanese larch & $72 \pm 1$ & $4.3 \pm 1.9$ & $35 \pm 11$ \\
\hline
\end{tabular}

Green moisture content and density

The results of the green moisture content and density of Dahurian larch and Japanese larch wood are shown in Tab. 3. The green moisture content in sapwood and heartwood of Dahurian larch wood was $85.3 \%$ and $61.8 \%$, and that of Japanese larch wood was $74.1 \%$ and $35.7 \%$, respectively. As a result, both sapwood and heartwood in Dahurian larch wood had higher green moisture content than that in Japanese larch wood. Shin and Kim (2003) reported that the green moisture content in Japanese larch wood was $80-109.7 \%$ in sapwood and $34.1-38.1 \%$ in heartwood, with a similar result as ours.

There was a considerable difference in green, air-dried, and oven-dried densities between the two species, as shown in Tab. 3. The green density of Dahurian larch wood was $1.06 \mathrm{~g}^{\mathrm{cm}} \mathrm{cm}^{-3}$ is remarkably higher than that of Japanese larch wood, which had a density of $0.79 \mathrm{~g} \cdot \mathrm{cm}^{-3}$. There was no difference between sapwood and heartwood in the green density of Dahurian larch wood, but Japanese larch wood showed a large difference with $0.90 \mathrm{~g} \cdot \mathrm{cm}^{-3}$ in sapwood and $0.69 \mathrm{~g} \cdot \mathrm{cm}^{-3}$ in heartwood. In Dahurian larch wood, the air-dried and oven-dried densities in heartwood of $0.84 \mathrm{~g} \cdot \mathrm{cm}^{-3}$ and $0.75 \mathrm{~g} \cdot \mathrm{cm}^{-3}$ were higher than those in sapwood of $0.66 \mathrm{~g} \cdot \mathrm{cm}^{-3}$ and $0.64 \mathrm{~g}^{\cdot \mathrm{cm}^{-3}}$. Contrasting this, for Japanese larch wood, there was no difference in air-dried and oven-dried densities between sapwood and heartwood. As a result, the green, air-dried, and oven-dried densities of Dahurian larch wood were larger than those of Japanese larch wood. Hwang et al. (2008) reported the air-dried and oven-dried densities of Dahurian larch wood as $0.73 \mathrm{~g} \cdot \mathrm{cm}^{-3}$ and $0.70 \mathrm{~g} \mathrm{~cm}^{-3}$, respectively. Jung and Park (2008) presented the green density, air-dried, and ovendried densities of Japanese larch wood as $0.79 \mathrm{~g} \cdot \mathrm{cm}^{-3}, 0.61 \mathrm{~g} \cdot \mathrm{cm}^{-3}$, and $0.56 \mathrm{~g} \cdot \mathrm{cm}^{-3}$, respectively. In addition, Han et al. (2017) reported that the oven-dried densities in Dahurian larch and Japanese larch wood were $0.72 \mathrm{~g} \cdot \mathrm{cm}^{-3}$ and $0.60 \mathrm{~g} \cdot \mathrm{cm}^{-3}$, respectively. As mentioned above, the previous findings on green moisture content and densities showed a trend that is like our findings.

Tab. 3: Green moisture content and density of the sample wood species.

\begin{tabular}{|l|c|c|c|c|}
\hline \multicolumn{1}{|c|}{ Properties } & Species & Sapwood & Heartwood & Average \\
\hline \multirow{2}{*}{ Green Moisture content $(\%)$} & Dahurian larch & $85.3 \pm 5.7$ & $61.8 \pm 2.7$ & $73.4 \pm 13.2$ \\
\cline { 2 - 5 } & Japanese larch & $74.1 \pm 1.5$ & $35.7 \pm 1.4$ & $55.0 \pm 22.1$ \\
\hline \multirow{2}{*}{ Green density $\left(\mathrm{M}_{\mathrm{g}} / \mathrm{V}_{\mathrm{g}}\right)\left(\mathrm{g} \cdot \mathrm{cm}^{-3}\right)$} & Dahurian larch & $1.04 \pm 0.02$ & $1.07 \pm 0.06$ & $1.06 \pm 0.06$ \\
\cline { 2 - 5 } & Japanese larch & $0.90 \pm 0.03$ & $0.69 \pm 0.03$ & $0.79 \pm 0.13$ \\
\hline \multirow{2}{*}{ Air-dried density $\left(\mathrm{M}_{\mathrm{a}} / \mathrm{V}_{\mathrm{a}}\right)\left(\mathrm{g} \cdot \mathrm{cm}^{-3}\right)$} & Dahurian larch & $0.66 \pm 0.05$ & $0.84 \pm 0.04$ & $0.75 \pm 0.10$ \\
\cline { 2 - 5 } & Japanese larch & $0.57 \pm 0.01$ & $0.58 \pm 0.02$ & $0.58 \pm 0.02$ \\
\hline \multirow{2}{*}{ Oven-dried density $\left(\mathrm{M}_{\mathrm{o}} / \mathrm{V}_{\mathrm{o}}\right)\left(\mathrm{g} \cdot \mathrm{cm}^{-3}\right)$} & Dahurian larch & $0.64 \pm 0.04$ & $0.75 \pm 0.03$ & $0.70 \pm 0.06$ \\
\cline { 2 - 5 } & Japanese larch & $0.57 \pm 0.01$ & $0.56 \pm 0.02$ & $0.56 \pm 0.02$ \\
\hline
\end{tabular}

Note: $M_{g}$ - green weight; $M_{a}$ - air-dried weight; $M_{o}$ - oven-dried weight; $V_{g}$ - green volume; $V_{a}$ - airdried volume; $V_{0}$ - oven-dried volume. 


\section{Shrinkage}

The results of the shrinkages in the volumetric, radial, and tangential directions and the coefficients of shrinkage anisotropy of Dahurian larch and Japanese larch wood are presented in Tab. 4. There were significant differences in the shrinkages and the coefficients of shrinkage anisotropy between the species. The volumetric, radial, and tangential shrinkage and the coefficient of shrinkage anisotropy in Dahurian larch wood were slightly higher than those in Japanese larch wood. There was little difference between sapwood and heartwood in the shrinkage values of Dahurian larch and Japanese larch wood. Chauret et al. (2002) reported the radial and tangential shrinkages of Dahurian larch wood grown in Canada as $3.9 \%$ and $9.7 \%$, the coefficient of shrinkage anisotropy as 2.5 , and volumetric shrinkage as $13.30 \%$. The differences in the shrinkage and coefficient of shrinkage anisotropy of both the species have been earlier reported in agreement with our findings (Bao et al. 2001, Jung and Park 2008). Bao et al. (2001) reported that the radial and tangential shrinkages of Japanese larch wood grown in China were 4.3-4.9\% and 6.5-6.8\%, respectively, and those of Dahurian larch wood were $3.24-4.51 \%$ and $8.01-9.13 \%$, respectively. Further, the coefficient of shrinkage anisotropy was 1.72-2.25 in Japanese larch wood and 1.79-2.78 in Dahurian larch wood. Jung and Park (2008) also reported that the radial and tangential shrinkages of Japanese larch wood were $4.67 \%$ and $8.44 \%$, respectively.

Tab. 4: Shrinkage of the sample wood species.

\begin{tabular}{|c|c|c|c|c|c|c|c|}
\hline Shrinkage & Species & Sapwood & $\mathrm{p}$-value & Heartwood & $\mathrm{p}$-value & Average & $\mathrm{p}$-value \\
\hline \multirow{2}{*}{$\mathrm{S}_{\mathrm{lo}}(\%)$} & Dahurian larch & $0.02 \pm 0.01$ & \multirow{2}{*}{$0.008^{*}$} & $0.05 \pm 0.04$ & \multirow{2}{*}{$0.000^{*}$} & $0.04 \pm 0.02$ & \multirow{2}{*}{$0.000^{*}$} \\
\hline & Japanese larch & $0.30 \pm 0.15$ & & $0.24 \pm 0.07$ & & $0.27 \pm 0.10$ & \\
\hline \multirow{2}{*}{$\mathrm{S}_{\mathrm{ro}}(\%)$} & Dahurian larch & $4.96 \pm 0.13$ & \multirow{2}{*}{0.123} & $4.22 \pm 0.21$ & \multirow{2}{*}{0.162} & $4.61 \pm 0.39$ & \multirow{2}{*}{$0.015^{*}$} \\
\hline & Japanese larch & $4.26 \pm 0.37$ & & $4.03 \pm 0.36$ & & $4.14 \pm 0.27$ & \\
\hline \multirow{2}{*}{$\mathrm{S}_{\text {to }}(\%)$} & Dahurian larch & $8.44 \pm 0.26$ & \multirow{2}{*}{$0.045^{*}$} & $8.38 \pm 0.24$ & \multirow{2}{*}{$0.000^{*}$} & $8.38 \pm 0.19$ & \multirow{2}{*}{$0.000^{*}$} \\
\hline & Japanese larch & $7.09 \pm 0.46$ & & $6.49 \pm 0.42$ & & $6.74 \pm 0.50$ & \\
\hline \multirow{2}{*}{$\mathrm{S}_{\mathrm{vo}}(\%)$} & Dahurian larch & $12.95 \pm 0.20$ & \multirow{2}{*}{$0.043^{*}$} & $12.25 \pm 0.33$ & \multirow{2}{*}{$0.000^{*}$} & $12.65 \pm 0.37$ & \multirow{2}{*}{$0.000^{*}$} \\
\hline & Japanese larch & $11.00 \pm 0.80$ & & $10.30 \pm 0.66$ & & $10.63 \pm 0.65$ & \\
\hline \multirow{2}{*}{$\mathrm{S}_{\mathrm{to}} / \mathrm{S}_{\mathrm{ro}}$} & Dahurian larch & 1.70 & \multirow{2}{*}{0.368} & 1.99 & \multirow{2}{*}{$0.000^{*}$} & 1.84 & \multirow{2}{*}{$0.006^{*}$} \\
\hline & Japanese larch & 1.66 & & 1.62 & & 1.64 & \\
\hline
\end{tabular}

Note: * difference was significance at level $0.05 \% . \mathrm{S}_{\mathrm{lo}}$ - total shrinkage in longitudinal direction; $\mathrm{S}_{\mathrm{ro}}$ - total shrinkage in radial direction; $\mathrm{S}_{\text {to }}$ - total shrinkage in tangential direction; $\mathrm{S}_{\text {to }} / \mathrm{S}_{\mathrm{ro}}$ - coefficient of shrinkage anisotropy; $\mathrm{S}_{\mathrm{vo}}$ - Volumetric shrinkage.

\section{Mechanical properties}

\section{Compressive properties and shearing strength}

The compressive properties and shearing strength of Dahurian larch and Japanese larch wood are shown in Tab. 5. The average values of axial compressive strength and Young's modulus of the two species showed little difference, but there were significant differences in the compression strength parallel to the grain and the Young's modulus between sapwood and heartwood in both species. In heartwood, the compression strength parallel to grain and Young's modulus of Dahurian larch wood were higher than those of Japanese larch wood. However, in sapwood, the compression strength parallel to grain of Dahurian larch wood was lower than that of Japanese larch wood, and the Young's modulus showed insignificant differences between the two species. Hwang et al. (2008) and Hwang and Park (2007) reported the compression 
strength parallel to grain of Dahurian larch wood as 60.6 $\mathrm{MPa}$ and 66.7 $\mathrm{MPa}$, respectively. Jung and Park (2008) reported the compression strength parallel to grain of Japanese larch wood as 52.1 MPa. Kwon et al. (2004) described the compression strength parallel to grain and Young's modulus of Japanese larch wood as 58.8 MPa and $1960 \mathrm{MPa}$, respectively, which were lower values than those in this study. The average values in shearing strength of the two species showed little difference, but there was a significant difference in the shearing strength of heartwood of both species, i.e., in heartwood, the shearing strength of Dahurian larch wood was higher than that of Japanese larch wood. Hwang et al. (2008) and Hwang and Park (2007) reported the shearing strength of Dahurian larch wood as 13.3 MPa and 11.5 MPa. Furthermore, Jung and Park (2008) and Kwon et al. (2004) reported the shearing strength of Japanese larch wood as $10.8 \mathrm{MPa}$ and $8.4 \mathrm{MPa}$, respectively, which are similar to the values obtained in this study. As a result, there were no significant differences in the compressive properties and shearing strengths between the two species. Nevertheless, the compressive properties and shearing strengths were significantly different between sapwood and heartwood in both species at the $5 \%$ level, except for the Young's modulus and shearing strength in sapwood (Tab. 5).

Tab. 5: Compressive properties and shearing strength of the sample wood species.

\begin{tabular}{|c|c|c|c|c|c|c|c|}
\hline Properties & Species & Sapwood & p-value & Heartwood & $\mathrm{p}$-value & Average & p-value \\
\hline \multirow{2}{*}{$\begin{array}{l}\text { Compression strength } \\
\text { parallel to grain }(\mathrm{MPa})\end{array}$} & Dahurian larch & $60.2 \pm 3.3$ & \multirow{2}{*}{$0.002^{*}$} & $83.2 \pm 4.3$ & \multirow{2}{*}{$0.001^{*}$} & $70.6 \pm 12.5$ & \multirow{2}{*}{0.910} \\
\hline & Japanese larch & $68.2 \pm 3.4$ & & $72.2 \pm 3.7$ & & $70.2 \pm 3.9$ & \\
\hline \multirow{2}{*}{$\begin{array}{l}\text { Young`s modulus in } \\
\text { compression }(\mathrm{MPa})\end{array}$} & Dahurian larch & $2,419 \pm 579$ & \multirow{2}{*}{0.589} & $3,335 \pm 140$ & \multirow{2}{*}{$0.015^{*}$} & $2,928 \pm 607$ & \multirow{2}{*}{0.127} \\
\hline & Japanese larch & $2,559 \pm 316$ & & $2,649 \pm 514$ & & $2,604 \pm 415$ & \\
\hline \multirow{2}{*}{$\begin{array}{l}\text { Shearing strength } \\
(\mathrm{MPa})\end{array}$} & Dahurian larch & $9.1 \pm 1.4$ & \multirow{2}{*}{0.668} & $12.1 \pm 2.6$ & \multirow{2}{*}{$0.043^{*}$} & $10.6 \pm 2.5$ & \multirow{2}{*}{0.157} \\
\hline & Japanese larch & $8.8 \pm 1.5$ & & $9.8 \pm 1.8$ & & $9.3 \pm 1.7$ & \\
\hline
\end{tabular}

Note: * difference was significance at level $0.05 \%$.

\section{Hardness}

The hardness results of Dahurian larch and Japanese larch wood are shown in Tab. 6 . The average values of hardness in the cross and radial sections between the two species were significantly different.

Tab. 6: Hardness of the sample wood species.

\begin{tabular}{|c|c|c|c|c|c|c|c|}
\hline Sections & Species & Sapwood & p-value & Heartwood & p-value & Average & p-value \\
\hline \multirow{2}{*}{ Cross $(\mathrm{MPa})$} & Dahurian larch & $32.1 \pm 3.0$ & \multirow{2}{*}{$0.002^{*}$} & $45.3 \pm 3.5$ & \multirow{2}{*}{$0.025^{*}$} & $38.7 \pm 7.7$ & \multirow{2}{*}{$0.030^{*}$} \\
\hline & Japanese larch & $42.9 \pm 2.2$ & & $53.0 \pm 3.4$ & & $48.4 \pm 6.5$ & \\
\hline \multirow{2}{*}{ Radial (MPa) } & Dahurian larch & $10.2 \pm 1.3$ & \multirow{2}{*}{$0.000^{*}$} & $17.6 \pm 1.9$ & \multirow{2}{*}{0.553} & $13.8 \pm 4.4$ & \multirow{2}{*}{$0.048^{*}$} \\
\hline & Japanese larch & $16.8 \pm 0.9$ & & $18.6 \pm 2.2$ & & $18.2 \pm 1.9$ & \\
\hline \multirow{2}{*}{ Tangential (MPa) } & Dahurian larch & $8.2 \pm 1.2$ & \multirow{2}{*}{$0.003^{*}$} & $19.6 \pm 1.6$ & \multirow{2}{*}{0.262} & $13.9 \pm 6.4$ & \multirow{2}{*}{0.211} \\
\hline & Japanese larch & $17.5 \pm 4.2$ & & $17.8 \pm 1.6$ & & $17.7 \pm 2.8$ & \\
\hline
\end{tabular}

Note: ${ }^{*}$ difference was significance at level $0.05 \%$.

In both sapwood and heartwood, the hardness of Japanese larch wood was mostly higher than that of Dahurian larch wood. In addition, the hardness of heartwood in the two species was higher than that of sapwood. In the three sections, the hardness of the cross section was the largest, and those of the radial and tangential sections were similar. Tsoumis (1991) explained that the hardness is higher-up to about double in the cross section than radial and tangential sections. Chauret et al. (2002) reported the hardness in the cross-section of Dahurian larch wood grown in Canada as $44.3 \mathrm{MPa}$. Jung and Park (2008) reported the hardness of Japanese larch wood as $77.4 \mathrm{MPa}$ in the cross-section, 21.6 $\mathrm{MPa}$ in the radial section, and 16.7 $\mathrm{MPa}$ in the tangential section. 


\section{Relationship between physical and mechanical properties}

The relationships between the mechanical properties and growth ring width in both wood species are shown in Fig. 1. There was a negative correlation between growth ring width and Young's modulus in compression, however, a positive correlation was found between growth ring width and hardness in the cross section (Fig. 1). It seems that there was no correlation between growth ring width and compression strength parallel to grain and shearing strength (not shown here). In addition, there was little correlation between the compressive properties and shearing strength and latewood percentage (not shown here). On the other hand, there was a significant positive correlation in compression strength parallel to grain and shearing strength to oven-dried density (Fig. 2). Zhang (1995) reported that the mechanical properties of softwood and hardwood species are significantly correlated with growth ring width. Tsoumis (1991) explained that the latewood percentage in softwood tends to decrease with increasing growth ring width, that fastgrowing trees produce low strength wood, and that density is the best and simplest index of wood strength, which increases with increasing strength. Kollmann and Côté (1968) reported that the compressive strength and shearing strength in pine and ash woods increased with increasing density. Koizumi et al. (2003) and Jelonek et al. (2009) reported that axial compressive strength of Larix species has a high correlation with density. In addition, Riyanto and Gupta (1996) reported that the shearing strength of Douglas-fir has a positive correlation with oven-dried density, showing a tendency similar to that in this study.
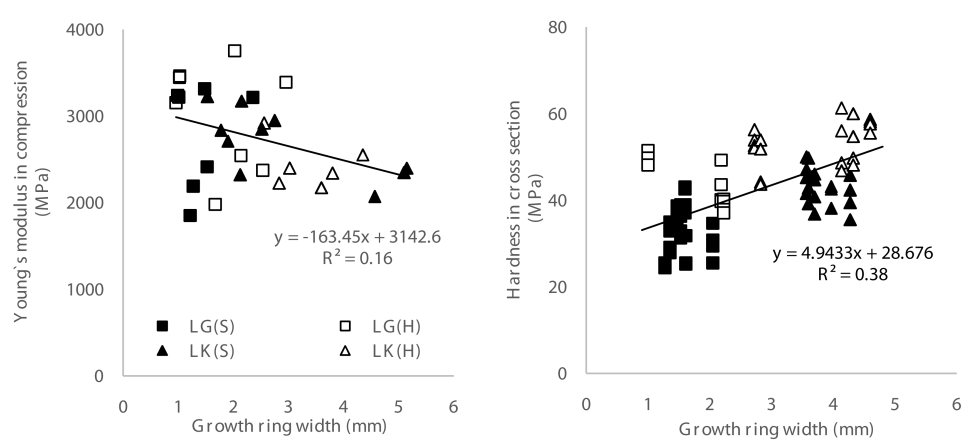

Fig. 1: Relationship between mechanical properties and growth ring width in the sample species: $L G$ - Larix gmelinii; LK - Larix kaempferi; (S) - sapwood; (H) - heartwood.
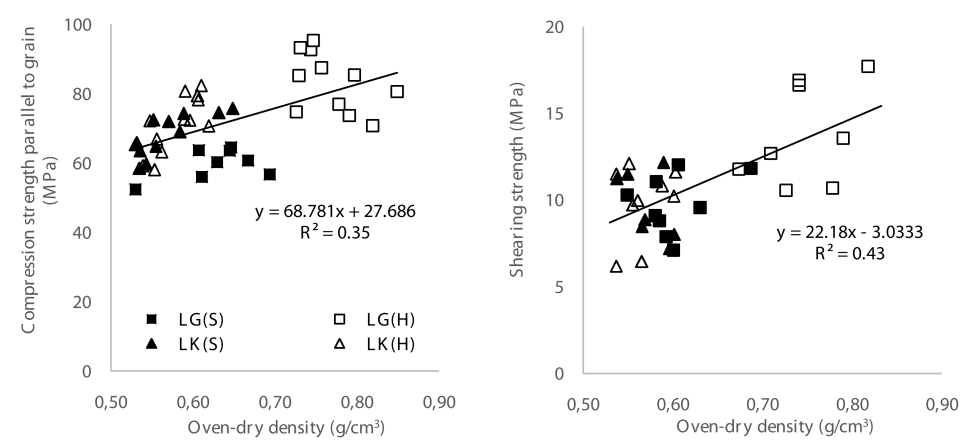

Fig. 2: Relationship between mechanical properties and oven-dried density in the sample species. 
The relationships between the physical properties and hardness in the three sections of both wood species are presented in Figs. 3-5. In Dahurian larch wood, there was a positive correlation between the hardness of the three sections and both latewood percentage and oven-dried density. In particular, the hardness in the tangential section showed a relatively high correlation with the latewood percentage and oven-dried density. In Japanese larch wood, however, there was no correlation between hardness and physical properties (not shown in this paper). Tsoumis (1991) explained that the relationship between density and hardness varies with species, but in most cases it is linear. In addition, linear relationships between density and hardness have been reported using Scots pine (Holmberg 2000) and birch species (Heräjärvi 2004). Kollmann and Côté (1968) described that the hardness value in air-dried American wood species showed a proportional relationship with density. Mikkola and Korhonen (2013) reported that the hardness of Scots pine had a positive correlation with latewood percentage, which was similar to the trend observed in this study.
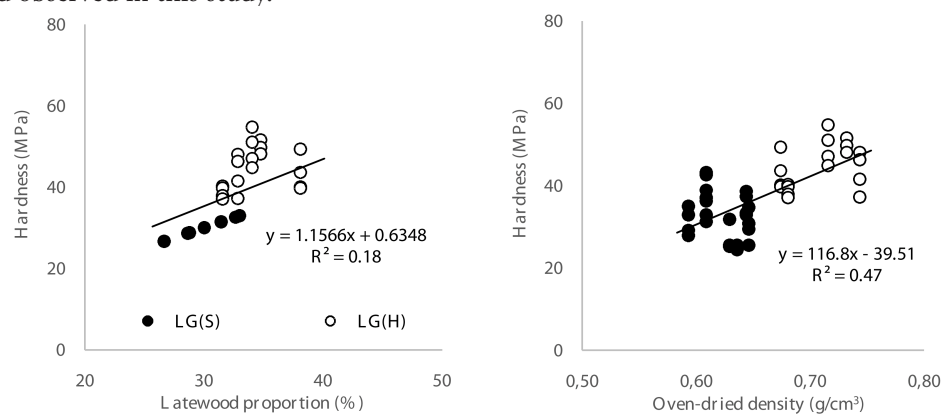

Fig. 3: Relationship between physical properties and hardness in the cross-section of Dahurian larch.
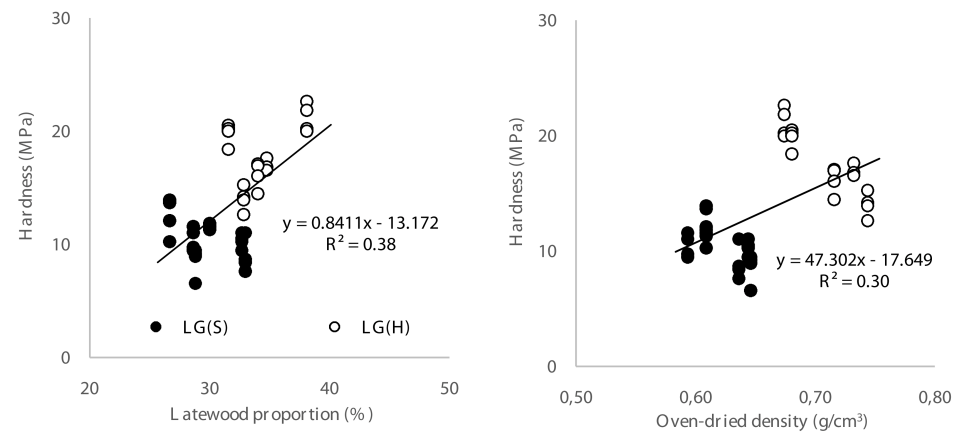

Fig. 4: Relationship between physical properties and hardness in the radial section of Dahurian larch.
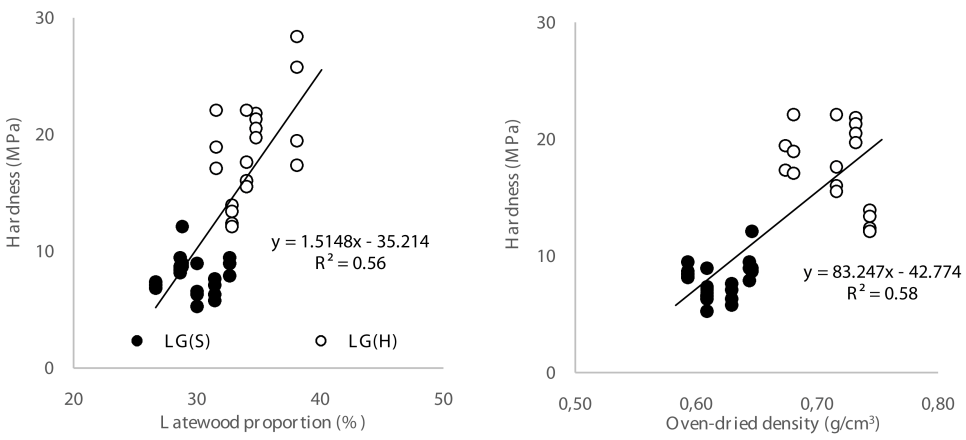

Fig. 5: Relationship between physical properties and hardness in the tangential section of Dahurian larch. 


\section{CONCLUSIONS}

(1) The heartwood proportion and latewood percentage of Dahurian larch wood were higher than those of Japanese larch wood. The growth ring width in Japanese larch wood was wider than that in Dahurian larch wood. (2) The green moisture content and density of Dahurian larch wood were higher than those of Japanese larch wood. In particular, the green density in Japanese larch wood and the air-dried and oven-dried density in Dahurian larch wood showed a large difference between sapwood and heartwood. (3) The shrinkage properties of Dahurian larch wood were higher than those of Japanese larch wood. (4) The compressive properties and shearing strength between Dahurian larch and Japanese larch wood showed little difference. However, there were significant differences in the heartwood of the two species. (5) Japanese larch wood had a higher hardness than Dahurian larch wood. The hardness in the cross and radial sections between the two species was significantly different. Further, the hardness of heartwood in the two species was higher than that of sapwood. (6) The compressive properties and shearing strength in both wood species were significantly correlated with oven-dried density compared to growth ring width and latewood percentage. The hardness of Dahurian larch wood showed a significant correlation with latewood percentage and oven-dried density.

\section{ACKNOWLEDGMENT}

This study was carried out with the support of the Research Project on Development of Thinning Effect Model and Long-term Monitoring for Major Species in National Forest (Project No. 120180621) funded by Korea Forest Service in 2017, Basic Science Research Program through NRF funded by the Ministry of Education (No. 2018R1A6A1A03025582), and also Basic Science Research Program through the National Research Foundation of Korea (NRF) funded by the Ministry of Education (NRF-2016R1D1A1B01008339).

\section{REFERENCES}

1. Bao, F.C., Jiang, Z.H., Jiang, X.M., Lu, X.X., Luo, X.Q. Zhang, S.Y., 2001: Differences in wood properties between juvenile wood and mature wood in 10 species grown in China. Wood Science and Technology 35(4): 363-375.

2. Chauret, G., Zhang, T., Lévesque, Y., 2002: Wood characteristics and end-use potential of two fast-growing exotic larch species (Larix gmelinii and Larix sibirica) grown in Ontario. Forint Canada Corporation, Report Project: 3563.

3. Choi, Y.S., Oh, S.M., Kim, G.H., 2011: Evaluation of pretreatment moisture content and fixation characteristics of treated wood for pressure treatment of Japanese red pine and Japanese larch skin timber with ACQ, CUAZ and CuHDO. Journal of The Korean Wood Science and Technology 39(6): 481-489.

4. Han, L., Zhao, X., Zhou, H., Luo, X., 2019: Reliability analysis on compression strength property of Chinese larch visually-graded dimension lumber. Wood Research 64(3): 471-482.

5. Han, Y.J., Kim, M.J., Lee, H.M., Kang, J.T., Eom, C.D., 2017: Comparison of cellular anatomical, physical and mechanical properties between Dahurian larch and Japanese larch. Journal of the Korean Wood Science and Technology 45(5): 525-534. 
6. Heräjärvi, H., 2004: Variation of basic density and Brinell hardness within mature Finnish Betula pendula and B. pubescens stems. Wood and Fiber Science 36(2): 216-227.

7. Holmberg, H., 2000: Influence of grain angle on Brinell hardness of Scots pine (Pinus sylvestris L.). Holz als Roh-und Werkstoff 58(1-2): 91-95.

8. Hwang, K.H., Park, B.S., 2007: Strength properties of old Korean larch pile. Journal of The Korean Wood Science and Technology 35(6): 23-30.

9. Hwang, K.H., Park, B.S., Park, M.J., 2008: Wood quality and strength properties of old structural members. Journal of the Korean Wood Science and Technology 36(1): 36-44.

10. Ishiguri, F., Iki, T., Otsuka, K., Takahashi, Y., Nezu, I., Tumenjargal, B., Ohshima, J., Yokota, S., 2019: Wood and lumber properties of Larix gmelinii var. olgensis planted in Japan. BioResources 14(4): 8072-8081.

11. Ishikura, Y., Matsumoto, K., Ohashi, Y., 2012: Radial variation in partial compression properties perpendicular to the grain of Japanese larch (Larix kaempferi). Journal of Wood Science 58(5): 399-407.

12. Jelonek, T., Pazdrowski, W., Tomczak, A., Spława-Neyman, S., 2009: The effect of biological class and age on physical and mechanical properties of European larch (Larix decidua Mill.) in Poland. Wood Research 54(1): 1-14.

13. Jung, S.H., Park, B.S., 2008: Wood properties of the useful tree species grown in Korea. Pp 215-218, Korea Forest Research Institute.

14. Kim, S.H., Yang, I., Han, G., 2015: Effect of sawdust moisture content and particle size on the fuel characteristics of wood pellet fabricated with Quercus mongolica, Pinus densiflora, and Larix kaempferi sawdust. Journal of The Korean Wood Science and Technology 43(6): 757-767.

15. Koizumi, A., Takata, K., Yamashita, K., Nakada, R., 2003: Anatomical characteristics and mechanical properties of Larix sibirica grown in south-central Siberia. IAWA Journal 24(4): 355-370.

16. Kollmann, F.F.P., Côté, W.A., 1968: Principles of wood science and technology: I Solid Wood. Pp 342-343 and 404, Springer-Verlag, Berlin•Heidelberg. Germany.

17. KS F 2198, 2016: Determination of density and specific gravity of wood.

18. KS F 2199, 2016: Determination of moisture content of wood.

19. KS F 2202, 2016: Determination of average width of annual rings for wood.

20. KS F 2203, 2004: Method of shrinkage test for wood.

21. KS F 2206, 2004: Method of compression test for wood.

22. KS F 2209, 2004: Method of shear test for wood.

23. KS F 2212, 2004: Method of hardness test for wood.

24. Kwon, S.M., Hwang, W.J., Kwon, G.J., Kim, N.H., 2004: Wood quality of Pinus koraiensis and Larix kaempferi. Journal of Forest and Environmental Science 20: 170-181.

25. LePage, B.A., Basinger, J.F., 1995: The evolutionary history of the genus Larix (Pinaceae). USDA, Forest Service, Intermountain Research Station, GTR-INT, 319: 19-29.

26. Mikkola, M.T., Korhonen, R.K., 2013: Effect of latewood proportion on mechanical properties of Finnish pine wood modified with compression drying. Wood and Fiber Science 45(4): 335-342.

27. Pazdrowski, W., Jelonek, T., Tomczak, A., Stypuła, I., Spława-Neyman, S., 2007: Proportion of sapwood and heartwood and selected biometric features in larch trees (Larix decidua Mill.). Wood Research 52(4): 1-16.

28. Riyanto, D.S., Gupta, R., 1996: Effect of ring angle on shear strength parallel to the grain of wood. Forest Products Journal 46(7/8): 87-92. 
29. Shin, H.H., Kim, B.R., 2003: Studies on variability in wood quality in stem of Larix leptolepis-green moisture content and shrinkage between heartwood and sapwood. Journal of Korea Forestry Energy 22(1): 1-7.

30. Song, Y.J., Hong, S.I., 2018: Performance evaluation of the bending strength of larch cross-laminated timber. Wood Research 63(1): 105-116.

31. Tsoumis, G.T., 1991: Science and technology of wood: structure, properties, utilization. Pp 171-175, Van Nostrand Reinhold press. New York.

32. Wang, Z., Sun, B.L., Liu, J.L., 2017: Investigation of volatile products released during vacuum heat treatment of larch wood. Wood research 62(5): 773-782.

33. Zhang, S.Y., 1995: Effect of growth rate on wood specific gravity and selected mechanical properties in individual species from distinct wood categories. Wood Science and Technology 29(6): 451-465.

34. Zhou, H., Han, L., Ren, H., Lu, J., 2015: Size effect on strength properties of Chinese larch dimension lumber. BioResources 10(2): 3790-3797. 


\author{
Jung Kee Choi \\ Kangwon National University \\ College Of Forest And Environmental Sciences \\ 2434I Chunchoen \\ Republic Of Korea
}

Seong Hyun Kim, Do Hoon Kim, Jae Ix Jo, Jong Ho Kim, Seung Hwan Lee

Nam Hun Kim ${ }^{*}$

Kangwon National University

College Of Forest And Environmental Sciences

Department Of Forest Biomaterials Engineering

2434I Chunchoen

Republic Of Korea

*Corresponding author: kimnh@kangwon.ac.kr 